University of Nebraska - Lincoln

DigitalCommons@University of Nebraska - Lincoln

Faculty Publications from the Department of

Electrical and Computer Engineering

Electrical \& Computer Engineering, Department

$2-2018$

\title{
Condensation and subsequent freezing delays as a result of using femtosecond laser functionalized surfaces
}

Chongji Huang

Ryan Bell

Alfred Tsubaki

Craig Zuhlke

Dennis Alexander

Follow this and additional works at: https://digitalcommons.unl.edu/electricalengineeringfacpub

Part of the Computer Engineering Commons, and the Electrical and Computer Engineering Commons

This Article is brought to you for free and open access by the Electrical \& Computer Engineering, Department of at DigitalCommons@University of Nebraska - Lincoln. It has been accepted for inclusion in Faculty Publications from the Department of Electrical and Computer Engineering by an authorized administrator of DigitalCommons@University of Nebraska - Lincoln. 


\section{Condensation and subsequent freezing delays as a result of using femtosecond laser functionalized surfaces ${ }^{\circledR}$}

Cite as: J. Laser Appl. 30, 011501 (2018); https://doi.org/10.2351/1.4986058

Submitted: 16 May 2017 . Accepted: 10 November 2017 . Published Online: 04 January 2018

Chongji Huang, Ryan Bell, Alfred Tsubaki, Craig A. Zuhlke, and Dennis R. Alexander

COLLECTIONS

EP This paper was selected as an Editor's Pick
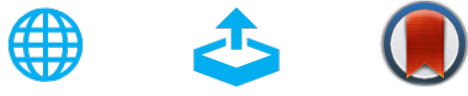

\section{ARTICLES YOU MAY BE INTERESTED IN}

Influence of baking conditions on 3D microstructures by direct laser writing in negative photoresist SU-8 via two-photon polymerization

Journal of Laser Applications 29, 042010 (2017); https://doi.org/10.2351/1.5010756

Formation mechanisms of pores and spatters during laser deep penetration welding

Journal of Laser Applications 30, 012002 (2018); https://doi.org/10.2351/1.4993843

Residual stress induced convex bending in laser peen formed aluminum alloy

Journal of Laser Applications 30, 012001 (2018); https://doi.org/10.2351/1.5012962

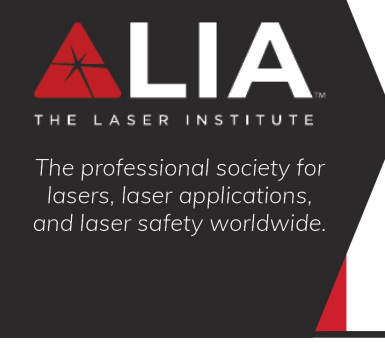

Become part of the LIA experience cultivating innovation, ingenuity, and inspiration within the laser community.

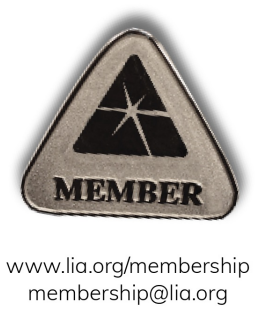

Find Out More 


\title{
Condensation and subsequent freezing delays as a result of using femtosecond laser functionalized surfaces
}

\author{
Chongji Huang, ${ }^{\text {a) }}$ Ryan Bell, Alfred Tsubaki, Craig A. Zuhlke, and Dennis R. Alexander \\ Department of Electrical and Computer Engineering, University of Nebraska-Lincoln, Lincoln, Nebraska 68588
}

(Received 16 May 2017; accepted for publication 10 November 2017; published 4 January 2018)

\begin{abstract}
In this paper, the authors report on the use of femtosecond laser surface processing (FLSP) to enhance the anti-icing properties of a commonly used aircraft alloy, Al 7075-O Clad. By changing the surface morphology through FLSP and the surface chemistry through siloxane vapor deposition, the wettability of Al 7075-O Clad was altered. Tall mound and short mound FLSP functionalized surfaces were created through two sets of laser parameters. Condensation and the subsequent freezing of condensates on FLSP Al 7075-O Clad was studied. Both structure height and surface wettability were shown to play a role in the delay of freezing. Freezing occurred on the FLSP superhydrophilic surface faster than on the unprocessed Al 7075-O Clad surface; however, freezing was delayed for all superhydrophobic FLSP surfaces. Tall structure height FLSP functionalized surfaces delayed freezing time longer than short structure height FLSP functionalized surfaces although all were superhydrophobic. It was shown that FLSP functionalized surfaces were able to delay freezing by up to $530 \mathrm{~s}$ compared with unprocessed Al 7075-O Clad. The authors also report on self-propelled condensate jumping on FLSP surfaces during the condensing process. The selfpropelled jumping phenomena provide a means to promote anti-icing of materials, especially where jumping drops can be swept away in flow conditions. (C) 2018 Laser Institute of America.
\end{abstract}

https://doi.org/10.2351/1.4986058

Key words: femtosecond laser surface processing, condensation, anti-icing, superhydrophobic, surface structures, freezing

\section{INTRODUCTION}

There are many applications where metallic anti-icing surfaces would be desirable. Typical applications include power line cables, aircraft, wind turbines, and cold weather marine applications. Various anti-icing studies have been reported in the previous publications. ${ }^{1-4}$ Surface wettability, which can be controlled by micro/nanoscale features along with surface chemistry, is an important parameter for controlling ice buildup. Superhydrophobic and hydrophobic surfaces have been shown to delay freezing on various substrates. ${ }^{1-3,5-9}$ In the work by Van Dyke et al., the relative humidity of the atmosphere was shown to be an important factor in icing due to condensation. ${ }^{9}$

Femtosecond laser surface processing (FLSP) has been previously shown to produce different self-organized micro/ nanoscale surfaces on metals. ${ }^{10}$ Structures produced through FLSP can be controlled by varying the laser fluence and pulse count. FLSP surfaces can be made superhydrophobic by vapor deposition. In this paper, we investigate the delay of condensation and subsequent freezing on superhydrophobic and superhydrophilic FLSP functionalized and unprocessed Al 7075-O Clad surfaces. Superhydrophobic FLSP functionalized tall mound surface delayed the time required for freezing of condensation the longest. We report for the

\footnotetext{
a) Author to whom correspondence should be addressed; electronic mail: chongjihuang@icloud.com
}

first time the impact of FLSP structures on the time required for freezing of condensation to occur.

Condensate on superhydrophobic surfaces has been shown to spontaneously jump upon coalescence. ${ }^{11}$ Self-propelled condensate jumping exhibits a self-cleaning effect, which has been shown to delay condensation and subsequent freezing time. ${ }^{12}$ In this paper, we present self-propelled jumping condensate on FLSP functionalized surfaces.

\section{EXPERIMENT}

\section{A. Sample fabrication}

Quasiperiodic microstructures covered with nanoparticles were produced through FLSP on various $40 \times 40 \times 1 \mathrm{~mm} \mathrm{Al}$ 7075-O Clad aircraft aluminum alloy samples. The laser used in this work was a Coherent, Astrella laser system, which produces $35 \mathrm{fs}, 800 \mathrm{~nm}$ pulses at a $1 \mathrm{kHz}$ repetition rate, with a maximum pulse energy of $6 \mathrm{~mJ}$. The size and shape of the FLSP micron scale features were modified by controlling the laser fluence and the number of laser pulses incident on the sample using a technique described by Zuhlke et al. ${ }^{10,13}$ The diagram of the laser experimental setup is shown in Fig. 1.

By varying the laser parameters, two different mound structures were created on Al 7075-O Clad. For tall mound surfaces, the laser fluence value was $6.03 \mathrm{~J} / \mathrm{cm}^{2}$ and the laser spot radius was $200 \mu \mathrm{m}$. Each region was irradiated with 341 pulses. For the short mound surfaces, the laser fluence value 


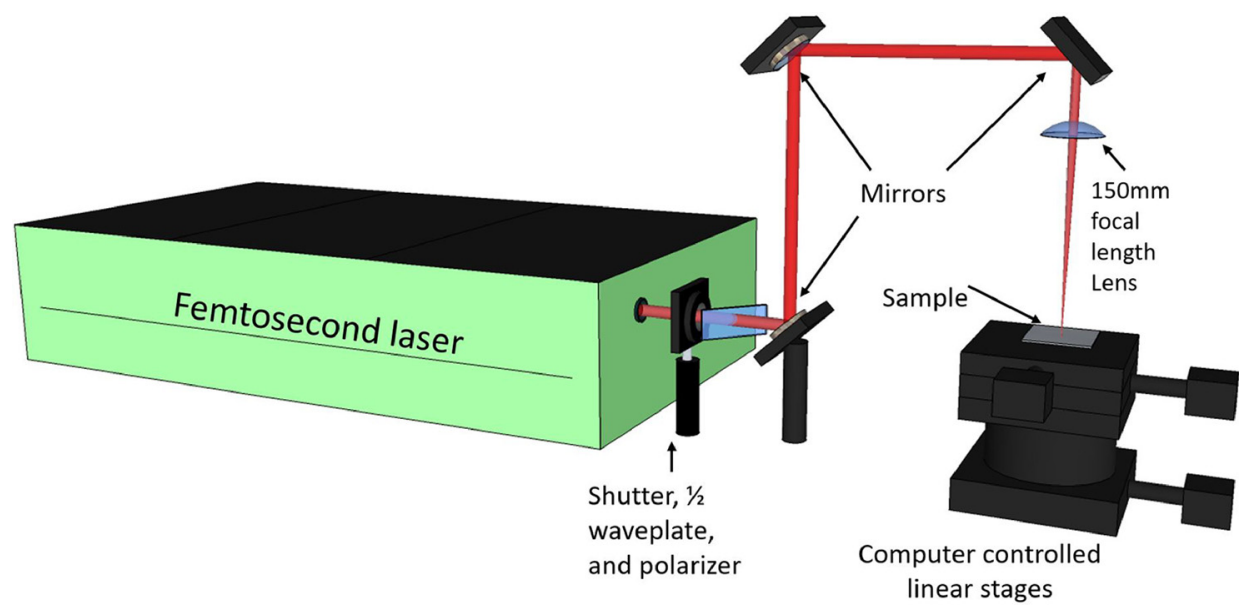

FIG. 1. Experimental setup utilized in this paper.

was $2.80 \mathrm{~J} / \mathrm{cm}^{2}$ and the laser spot radius was $282 \mu \mathrm{m}$. Each region was irradiated with 506 pulses.

\section{B. Surface wettability modification}

The intrinsically superhydrophilic FLSP Al 7075-O Clad surfaces were made superhydrophobic (functionalized) through vapor deposition of VMQ O-rings (McMaster-Carr 9396k105). The FLSP samples and the O-rings were placed on a Thermolyne Cimarec 2 heater and covered with a glass filter funnel. The samples were placed radially around the Orings. The FLSP surfaces were face up. The air temperature inside the funnel was kept at $182.1{ }^{\circ} \mathrm{C}$, measured by a thermocouple suspended inside the funnel. The heater plate temperature was $263.4^{\circ} \mathrm{C}$, measured with a thermocouple rested on top of the heater plate. The vapor deposition period was $2 \mathrm{~h}$. For the first $20 \mathrm{~min}$, the nozzle of the funnel was left open. After $20 \mathrm{~min}$, aluminum foil was used to seal the nozzle. One tall mound surface sample was kept superhydrophilic (referred to as superhydrophilic). All other FLSP samples were made superhydrophobic through vapor deposition of siloxanes (referred to as SMS1, SMS2, TMS1, and TMS2).

The intrinsic contact angle (CA) of all samples was measured using a Ramé-hart Goniometer/Tensiometer Model 790 with Advanced software. The water droplet size used for the contact angle measurements was $5 \mu \mathrm{l}$.

\section{Condensate freezing experiment system}

A Peltier cooler system was constructed with the following elements: a 2 Stage Peltier Module (Custom Thermoelectric 25412-5L31-07CQQ); a copper water block (Custom Thermoelectric WBA-1.62-0.55-CU-01); and a flat aluminum plate (Custom Thermoelectric CPT-2.25-1.62-0.25-AL). Excess heat from the Peltier cooler was dissipated through a copper cooling block supplied with chilled water at $5{ }^{\circ} \mathrm{C}$ supplied by a LYTRON circulating chiller (RC006G03BB1C002). The temperature of the flat aluminum plate was controlled with the following elements: a Kapton insulated K-type thermocouple (OMEGA 5TC-KK-K-20-72); a solid state relay (OMEGA SSRDC100VDC12); a proportional-integral-derivative (PID)
Controller (OMEGA CNI-16D44); and a voltage supply (KEPCO JQE 25-10M). The thermocouple was secured and thermally bonded (Omega OT-20-1/2) in the compression mounting of the flat aluminum plate. Samples were placed on the flat aluminum plate. Dry nitrogen gas at a velocity of approximately $20 \mathrm{~m} / \mathrm{s}$ was flowed over the samples to prevent condensation from occurring before the start of data collection. The voltage and current to the Peltier cooler were kept constant at $8 \mathrm{~V}$ and $3.85 \mathrm{~A}$, respectively. The PID controller was set to $-15^{\circ} \mathrm{C}$. The cycle time for the relay and PID controller was $1 \mathrm{~s}$. The assembled temperature controlled Peltier cooler system is shown in Fig. 2.

With the nitrogen gas flow on and the Peltier on, the samples cooled from room temperature at 22 to $-2.3 \pm 0.2^{\circ} \mathrm{C}$ ( \pm as standard deviation). The nitrogen flow was stopped when data recording was initiated. The temperature of the samples further decreased from -2.3 to $-15^{\circ} \mathrm{C}$, where it was kept constant by the PID controller switching the relay on and off. The relative humidity in the room was $25 \%$. Humidity and room temperature were measured using a dual humidity and temperature meter (McMaster-Carr 39175K21). The Peltier cooler system was mounted on the

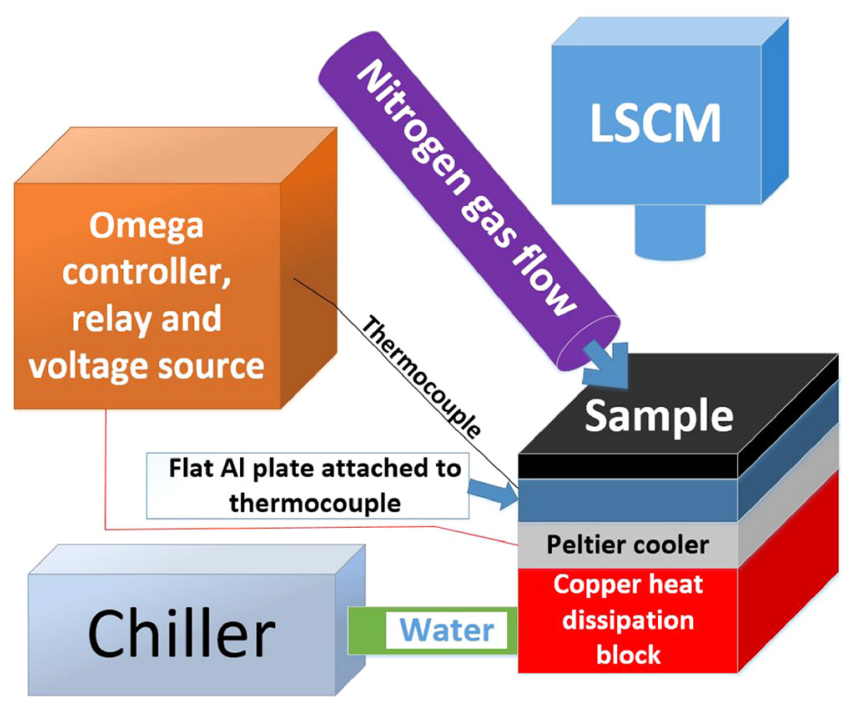

FIG. 2. Thermoelectric Peltier cooler system diagram. 

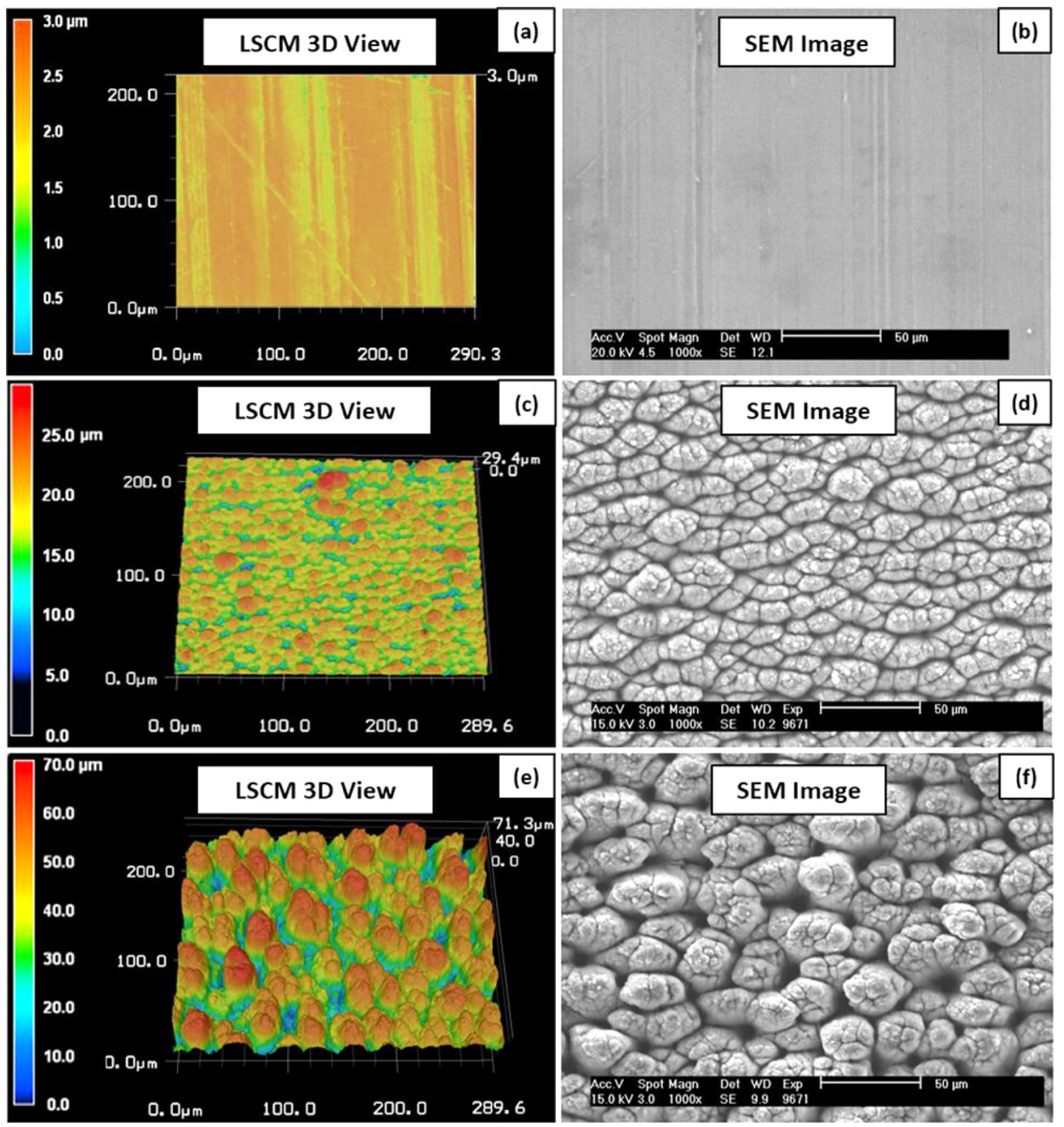

FIG. 3. (a) LSCM 3D view of unprocessed Al 7075-O Clad, (b) scanning electron microscope (SEM) image of unprocessed Al 7075-O Clad, (c) LSCM 3D view of short mound surface, (d) SEM image of short mound surface, (e) LSCM 3D view of tall mound surface, and (f) SEM image of tall mound surface.

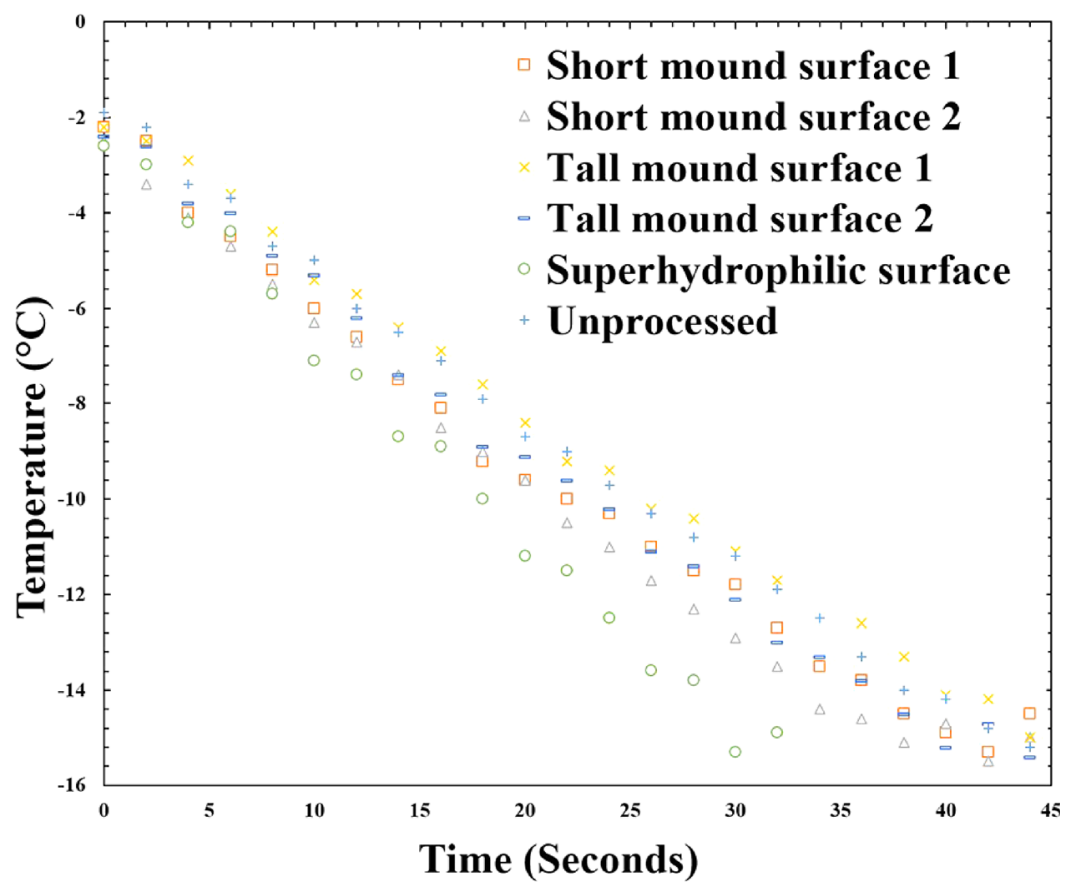

FIG. 4. Initial sample cooling from -2.3 to $-15^{\circ} \mathrm{C}$. 
TABLE I. Sample surface characteristics, CA before and after the experiment, and condensation and subsequent freezing.

\begin{tabular}{|c|c|c|c|c|}
\hline & $\begin{array}{c}\text { Average } \\
\text { height, } R_{z}(\mu \mathrm{m})\end{array}$ & $\begin{array}{c}\text { CA before } \\
\text { experiment (deg) }\end{array}$ & $\begin{array}{c}\text { CA after } \\
\text { experiment (deg) }\end{array}$ & $\begin{array}{l}\text { Entire surface } \\
\text { freezing time (s) }\end{array}$ \\
\hline Unprocessed Al 7075-O Clad & $1.2 \pm 0.6$ & $53 \pm 9$ & $77 \pm 2$ & 188 \\
\hline Superhydrophilic surface & $55.3 \pm 4.4$ & 0 & 0 & 41 \\
\hline SMS1 & $21.2 \pm 5.2$ & $168 \pm 2$ & $168 \pm 4$ & 545 \\
\hline SMS2 & $16.9 \pm 3.0$ & $170 \pm 4$ & $168 \pm 2$ & 567 \\
\hline Average data of SMS & $18.9 \pm 4.8$ & $169 \pm 2$ & $168 \pm 3$ & 556 \\
\hline TMS1 & $56.4 \pm 7.8$ & $168 \pm 3$ & $167 \pm 2$ & 696 \\
\hline TMS2 & $47.8 \pm 4.3$ & $169 \pm 3$ & $166 \pm 1$ & 718 \\
\hline Average data of TMS & $53.3 \pm 7.6$ & $168 \pm 3$ & $167 \pm 2$ & 707 \\
\hline
\end{tabular}

Keyence laser scanning confocal microscope (LSCM) VK9700 with the view centered on the samples. The LSCM optical microscope was used to monitor and record the videos of the condensation and subsequent freezing on the samples. The LSCM was used to measure average structure height $\left(R_{z}\right)$. The time required for condensate freezing is defined as when condensates from the atmosphere have frozen (solidified) over the entire surface being monitored by the optical view of the LSCM.

\section{Self-propelled jumping condensates}

Self-propelled jumping condensates on FLSP functionalized Al 7075-O Clad surfaces were observed at $8000 \mathrm{fps}$ and recorded using a Photron FASTCAM SA 1.1 HighSpeed camera, with a Nikon NIKKOR $105 \mathrm{~mm}$ 1:2.8 G ED microlens and $100 \mathrm{~mm}$ extensions tubes for increased magnification. The camera was at an incident angle of approximately $45^{\circ}$ to the samples. A Fiber-Lite high-intensity illuminator series 180 was used to illuminate the sample.

The samples' temperatures were dropped from room temperature at $18.5^{\circ} \mathrm{C}$ and were maintained at $-7^{\circ} \mathrm{C}$ by the PID controller. The temperature of the samples was controlled with the Peltier cooler system with no nitrogen flow. The relative humidity of the room was $25 \%$.

\section{RESULT AND DISCUSSION}

LSCM 3D view and SEM images of the unprocessed $\mathrm{Al}$ 7075-O Clad, and two structure subsets, SMS and TMS, are shown in Fig. 3.

After removing the nitrogen flow from the samples, each sample followed a similar cooling rate to $-15^{\circ} \mathrm{C}$ as shown in Fig. 4. It should be noted that the temperature of the

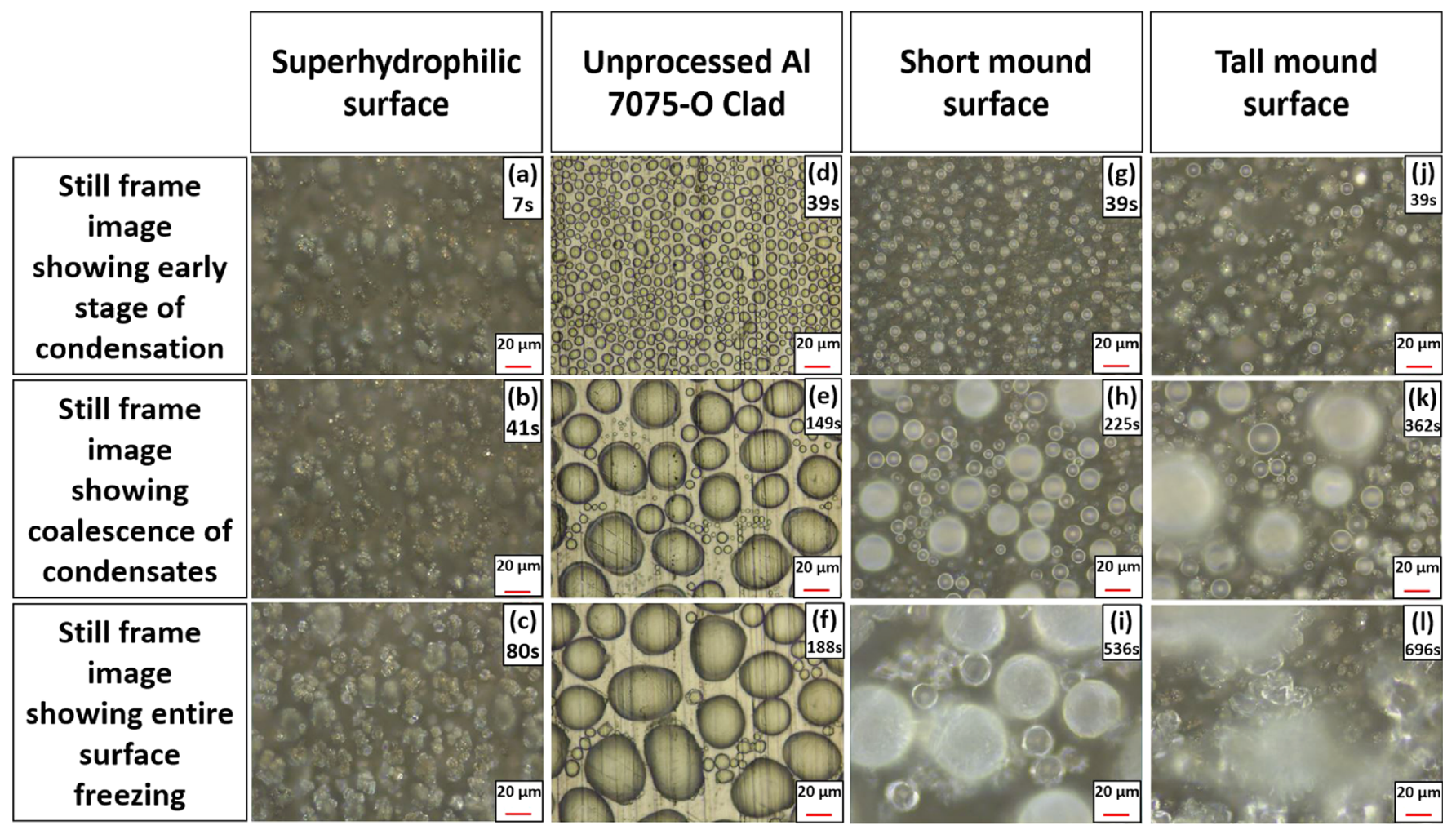

FIG. 5. Condensation and subsequent freezing progression images of superhydrophilic FLSP functionalized surface shown in (a), (b), and (c). Progression images of unprocessed Al 7075-O Clad surface shown in (d), (e), and (f). Progression images of SMS shown in (g), (h), and (i). Progression images of TMS shown in (j), (k), and (1). The videos of entire surface freezing for each sample are shown in videos $1-4$. The description and explanation for videos $1-4$ is in the supplementary material. ${ }^{19}$ 

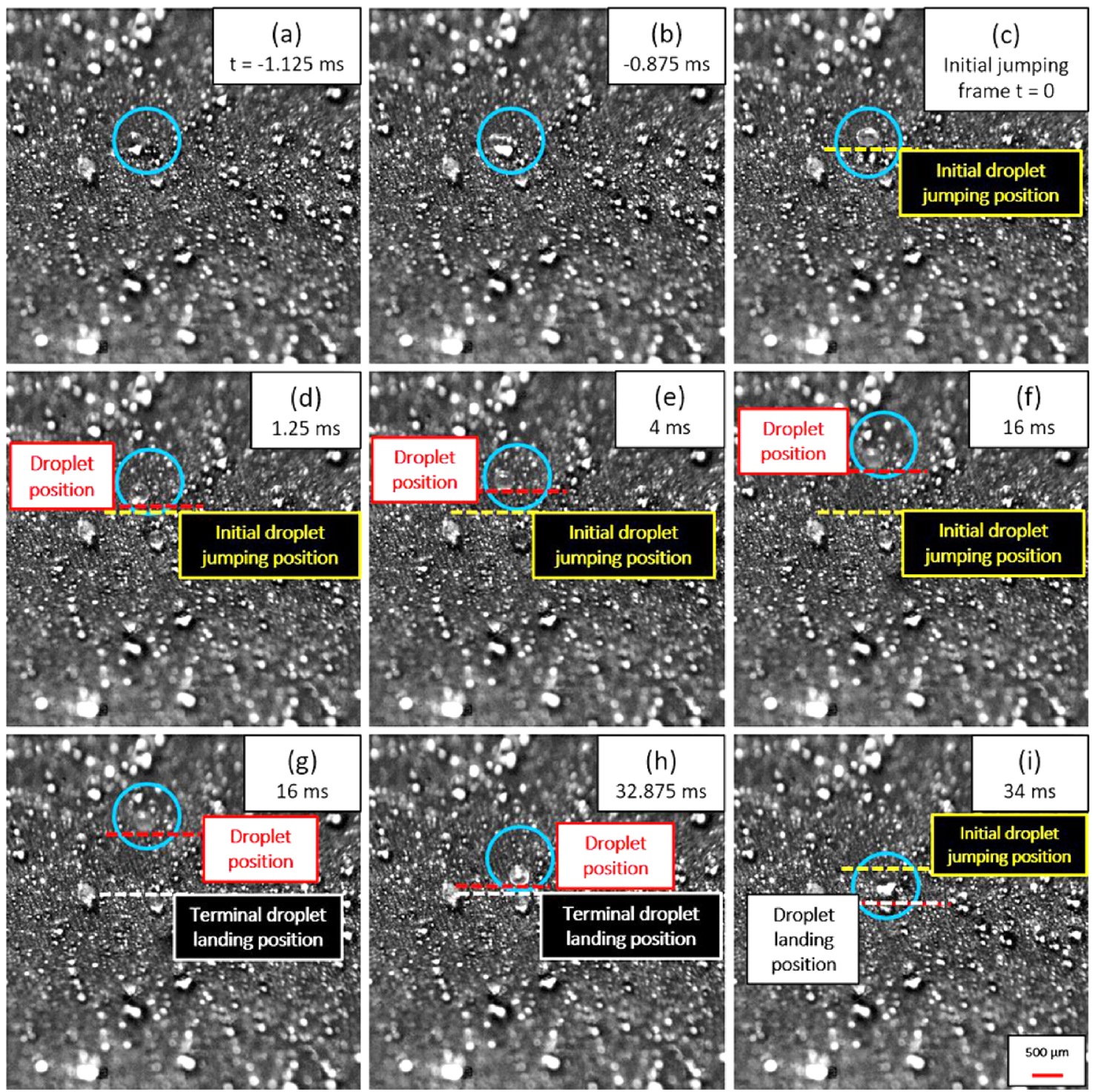

FIG. 6. Still frame images of two condensate drops combining [(a), (b), and (c)], jumping off the surface [(d), (e), and (f)], and falling due to gravity [(g), (h), and (i)]. The video of this progression is shown in video 5 .

superhydrophilic surface dropped faster than that of the other samples. The increased rate of temperature drop is contributed to the film condensation on the superhydrophilic surface which acts to insulate the surface from the atmosphere, while condensation on the other surfaces occurs in a dropwise manner.

The average structure height, CA before and after experiment, and time for freezing of each sample are shown in Table I. The time required to cool the samples to $-15^{\circ} \mathrm{C}$ is included in the entire surface freezing time.

The superhydrophilic sample froze faster (41s) than the unprocessed sample (188s). All superhydrophobic surfaces delayed freezing for at least $357 \mathrm{~s}$ after the unprocessed froze. It should be noted that the sample with a higher CA for each structure subset delayed freezing longer than their respective counterpart. Surface chemistry plays an important role in the delay of condensate freezing on FLSP structures of similar height. For equivalent sized droplets on superhydrophobic surfaces, the contact area for heat conduction is inversely proportional to the contact angle of the surface. The impact of CA has been previously shown to delay freezing of condensation on other substrates. ${ }^{14}$

Both TMS1 and TMS2 delayed the onset of freezing longer than SMS1 and SMS2. Thus, the structure morphology is important in delaying the freezing condensation. Both structure morphology and surface chemistry were important properties in delaying the onset of condensate freezing.

Still frame images (captured during LSCM optical view) of the progression of condensation and subsequent freezing on all sample subsets are shown in Fig. 5. Note that as the condensates freeze [Figs. 5(c), 5(f), 5(i), and 5(1)], the transparency and shape of the condensates are altered. The frozen condensates on SMS are more opaque than those on the TMS indicating that prior to freezing, condensates on SMS exist at a higher supercooling than on TMS. ${ }^{15,16}$ The transparency change is a result of rapid kinetic freezing of the condensates. ${ }^{17}$

As shown in Fig. 5, water vapor condenses into droplets on the unprocessed surface (d), SMS (g), and TMS (j), and the condensate drops grow $[(\mathrm{e}),(\mathrm{h})$, and $(\mathrm{k})]$, coalesce, and 
eventually freeze [(f), (i), and (l)]. On the superhydrophilic sample, condensate droplets are not easily observed; however, the growth and eventual freezing of a film of ice on the surface was observed (c).

Condensates on TMS and SMS exhibit self-propelled jumping away from the FLSP surface. Although selfpropelled condensate jumping has been shown on other superhydrophobic surfaces, ${ }^{12}$ it is the first time selfpropelled jumping has been reported in the literature on FLSP surfaces. A still image sequence of self-propelled condensate jumping on TMS1 is shown in Fig. 6.

Self-propelled condensate jumping is important for delaying the time required for freezing of condensation, as it acts to remove the droplets that can initiate freezing on the surface. Self-propelled condensate jumping is strongly influenced by the wettability. Wisdom et al. demonstrated a unique selfcleaning mechanism whereby the contaminated superhydrophobic surface is exposed to condensing water vapor, and the contaminants are autonomously removed by the self-propelled jumping motion of the resulting liquid condensate, which partially covers or fully encloses the contaminating particles. ${ }^{12}$ The higher the contact angle, the lower the energy required to detach a spherical particle from a flat interface. ${ }^{18}$

\section{CONCLUSION}

In this work, different FLSP functionalized Al 7075-O Clad samples were processed with different surface structures. The freezing time of unprocessed Al 7075-O Clad was $188 \mathrm{~s}$. The freezing time of superhydrophilic FLSP functionalized Al 7075-O Clad surface was $41 \mathrm{~s}$. The freezing time of SMS1 and SMS2 was $556 \pm 11 \mathrm{~s}$. The freezing time of TMS1 and TMS2 was $707 \pm 11$ s. Self-propelled condensate jumping on FLSP structures is shown for the first time.

\section{ACKNOWLEDGMENTS}

Research reported in this paper was supported by the Boeing Company: Boeing Research \& Technology No. SSOW-BRT-L1115-0083. Research was performed using equipment in the Nano-Engineering Research Core Facility (part of the Nebraska Nanoscale Facility), which is partially funded from the Nebraska Research Initiative.
${ }^{1}$ M. Lee, C. Yim, and S. Jeon, "Communication: anti-Icing characteristics of superhydrophobic surfaces Investigated by quartz crystal microresonators," J. Chem. Phys. 142, 041102 (2015).

${ }^{2}$ S. Farhadi, M. Farzaneh, and S. A. Kulinich, "Anti-icing performance of superhydrophobic surfaces,” Appl. Surf. Sci. 257, 6264-6269 (2011).

${ }^{3}$ S. A. Kulinich and M. Farzaneh, "Ice adhesion on super-hydrophobic surfaces," Appl. Surf. Sci. 255, 8153-8157 (2009).

${ }^{4}$ L. Makkonen, "Ice adhesion-theory, measurements and countermeasures," J. Adhes. Sci. Technol. 26, 413-445 (2012).

${ }^{5}$ S. Jung, M. Dorrestijn, D. Raps, A. Das, C. M. Megaridis, and D. Poulikakos, "Are superhydrophobic surfaces best for icephobicity?," Langmuir 27, 3059-3066 (2011).

${ }^{6}$ Q. Hao, Y. Pang, Y. Zhao, J. Zhang, J. Feng, and S. Yao, "Mechanism of delayed frost growth on superhydrophobic surfaces with jumping condensates: more than interdrop freezing," Langmuir 30, 15416-15422 (2014).

${ }^{7}$ C. Antonini, M. Innocenti, T. Horn, M. Marengo, and A. Amirfazli, "Understanding the effect of superhydrophobic coatings on energy reduction in anti-icing systems," Cold Reg. Sci. Technol. 67, 58-67 (2011).

${ }^{8}$ J. B. Boreyko and C. P. Collier, "Delayed frost growth on jumping-drop superhydrophobic surfaces," ACS Nano 7, 1618-1627 (2013).

${ }^{9}$ A. S. Van Dyke, D. Collard, M. M. Derby, and A. R. Betz, "Droplet coalescence and freezing on hydrophilic, hydrophobic, and biphilic surfaces," Appl. Phys. Lett. 107, 141602 (2015).

${ }^{10}$ C. a Zuhlke, T. P. Anderson, and D. R. Alexander, "Formation of multiscale surface structures on nickel via above surface growth and below surface growth mechanisms using femtosecond laser pulses," Opt. Express 21, 8460-8473 (2013).

${ }^{11}$ X. Qu, J. B. Boreyko, F. Liu, R. L. Agapov, N. V. Lavrik, S. T. Retterer, J. J. Feng, C. P. Collier, and C. H. Chen, "Self-propelled sweeping removal of dropwise condensate," Appl. Phys. Lett. 106, 221601 (2015).

${ }^{12}$ K. M. Wisdom, J. A. Watson, X. Qu, F. Liu, G. S. Watson, C.-H. Chen, Y. Wan, Z. Lian, Z. Liu, H. Yu, L. Dellieu, M. Sarrazin, P. Simonis, O. Deparis, J. P. Vigneron, M. J. Tobin, L. Puskar, J. Hasan, H. K. Webb, C. J. Hirschmugl, M. J. Nasse, and G. Gervinskas, "Self-cleaning of superhydrophobic surfaces by self-propelled jumping condensate," Proc. Natl. Acad. Sci. U. S. A. 116, $7992-7997$ (2013).

${ }^{13}$ C. A. Zuhlke, T. P. Anderson, and D. R. Alexander, "Comparison of the structural and chemical composition of two unique micro/nanostructures produced by femtosecond laser interactions on nickel," Appl. Phys. Lett. 103, 121603 (2013).

${ }^{14} \mathrm{P}$. Tourkine, M. Le Merrer, and D. Quéré, "Delayed freezing on water repellent materials," Langmuir 25, 7214-7216 (2009).

${ }^{15} \mathrm{M}$. Schremb and C. Tropea, "Solidification of supercooled water in the vicinity of a solid wall," Phys. Rev. E 94, 2-7 (2016).

${ }^{16}$ S. Jung, M. K. Tiwari, and D. Poulikakos, "Frost halos from supercooled water droplets," Proc. Natl. Acad. Sci. U. S. A. 109, 16073-16078 (2012).

${ }^{17}$ L. Oberli, D. Caruso, C. Hall, M. Fabretto, P. J. Murphy, and D. Evans, "Condensation and freezing of droplets on superhydrophobic surfaces," Adv. Colloid Interface Sci. 210, 47-57 (2014).

${ }^{18}$ B. P. Binks and T. S. Horozov, Colloidal Particles at Liquid Interfaces (Cambridge University Press, Cambridge, U. K., 2006).

${ }^{19}$ See supplementary material at https://doi.org/10.2351/1.4986058 for the video 1-5 and description of the videos. 